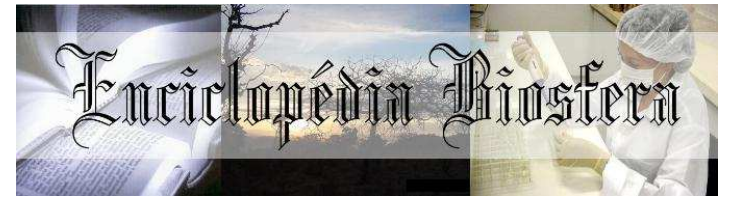

\title{
DIVERSIDADE DE ANUROS (AMPHIBIA: ANURA) EM FRAGMENTO VEGETACIONAL DE CERRADO NO MUNICÍPIO DE CAXIAS, MARANHÃO
}

José Rafael Sousa Bezerra ${ }^{1}$, Guilherme Sousa da Silva ${ }^{2}$, Ronison Ferreira Oliveira ${ }^{3}$, Gonçalo Mendes da Conceição ${ }^{4}$, Derise de Assunção Barbosa ${ }^{5}$

1 Graduado em Ciências Biológicas Licenciatura do Centro de Estudos

Superiores de Caxias da Universidade Estadual do Maranhão, Caxias/Maranhão

2 Mestrando do curso de Botânica do Instituto Nacional de Pesquisas da Amazônia, Manaus/Amazônia. E-mail: guilhermecx.cx@hotmail.com

3. Graduado em Ciências Biológicas Licenciatura do Centro de Estudos Superiores de Caxias da Universidade Estadual do Maranhão, Caxias/Maranhão

4 Professor Doutor da Universidade Estadual do Maranhão do Programa de Pós

Graduação em Biodiversidade, Ambiente e Saúde-PPGBAS, Caxias-MA

5 Professora Especialista da Unidade Integrada Municipal Felinto Batista Araújo, São João do Sóter-MA

Recebido em: 08/04/2017 - Aprovado em: 10/06/2017 - Publicado em: 20/06/2017 DOI: 10.18677/EnciBio_2017A108

O presente estudo teve como objetivo verificar a diversidade alfa de anfíbios (riqueza de espécies) na área de Proteção Ambiental do Inhamum, em Caxias-MA, um relevante fragmento vegetacional de Cerrado dentro do Estado. Foram realizadas expedições no período de julho de 2015, março a junho de 2016, na área em dois tipos de fisionomias: Mata de Galeria e Cerrado sujo. Para a coleta de animais foram utilizadas Armadilhas de interceptação e queda e método de busca ativa no período noturno e diurno quinzenalmente. Os animais capturados durante a vistoria e nas armadilhas foram visualizados e identificados no campo através de guias de identificação e confirmados por especialista na área, sendo todos registrados em caderno de campo, fotografados e logo após relocados no ambiente coletado. No levantamento realizado foram amostradas 24 espécies de Anfíbios. A família, gênero e espécie mais representativa foram respectivamente: Hylidae, Leptodactylus e Leptodactylus vastus. Dos ambientes investigados a maior incidência de anuros ocorreu em Mata de Galeria. Assim pode-se concluir que a biodiversidade alfa dentro da APA é significativamente rica, verificando a necessidade da conservação e manejo da mesma.

PALAVRAS-CHAVE: Herpetofauna, Levantamento Taxonômico, Sapos. 


\title{
DIVERSITY OF ANUROS (AMPHIBIA: ANURA) IN CERRADO VEGETATION FRAGMENT IN CAXIAS MUNICIPALITY, MARANHAO
}

\begin{abstract}
The present study aims to verify the alpha diversity (species richness) of amphibians in the Environmental Protection area of the Inhamum, in Caxias-MA, a relevant vegetation fragment of Cerrado within the State. Expeditions were carried out in the period from July 2015 and March to June 2016, in the area in two types of physiognomies: gallery forest and dirty Cerrado. For the collection of animals were used Traps of interception and fall and method of active search in the nocturnal and diurnal period fortnightly. The animals captured during the survey and in the traps were visualized and identified in the field through identification guides and confirmed by specialists in the area, all of them recorded in a field notebook, photographed and soon after being relocated to the collected environment. A total of 24 species of amphibians were sampled. The family, genus and most representative species were: Hylidae, Leptodactylus and Leptodactylus vastus. From the environments investigated, the highest incidence of anurans occurred in gallery forest. Thus it can be concluded that the alpha biodiversity within the APA is significantly rich, verifying the need for its conservation and management.
\end{abstract}

KEYWORDS: Herpetofauna, Taxonomic Survey, Frogs.

\section{INTRODUÇÃO}

A Herpetofauna brasileira apresenta uma das maiores riquezas do mundo, onde abriga várias espécies endêmicas, muitas das quais ameaçadas de extinção (DRUMMOND, 2005). São conhecidas no mundo 7.412 espécies de anfíbios (NEVES, 2015), sendo que no Brasil ocorrem 1.026 espécies (SBH, 2014).

Os anfíbios foram os primeiros vertebrados a viverem na Terra, sendo um grupo do qual os mamíferos e repteis incluindo aves, diversificaram, estando distribuídos atualmente em uma variedade de habitats e ecossistemas (CORRÊA, 2013). São ecologicamente importantes na dinâmica dos domínios fitogeográficos, pois desempenham a função primária de atuar como vetores no fluxo de nutrientes conectando ecossistemas aquáticos e terrestres, por possuírem pele permeável são animais extremamente sensíveis a poluição e a qualquer alteração no habitat, por isso são considerados excelentes bioindicadores e promissores na indústria farmacológica (ÁLVARES, 2009). Certas características fisiológicas e ecológicas tornam os anfíbios fortemente dependentes dos corpos hídricos, onde esses animais apresentam forte sensibilidade a alterações de parâmetros físicos e químicos da água (JIM, 1980; VAN-DAM \& BUSKENS, 1993; BURKETT \& THOMPSON, 1994; WATSON et al., 1995).

No geral, as intervenções humanas levam a um empobrecimento da estrutura e da diversidade da vegetação aumentando a degradação do ambiente (LIDDLE \& SCORGIE, 1980). Essas modificações nos ecossistemas alteram o hábitat de diversas espécies animais, causando a extinção de vários organismos (VAN ROOY \& STUMPEL, 1995).

O Cerrado é o segundo maior domínio morfoclimáticos e fitogeográfico do Brasil, possuindo uma alta riqueza de espécie e taxa de endemismo (SUGAI, 2010). Possui dessa forma uma elevada diversidade de anfíbios, sendo comparável à Herpetofauna da Amazônia quando expressa de maneira proporcional ao tamanho 
de cada bioma (OLIVEIRA \& MARQUIS, 2002). São conhecidas no Cerrado cerca de 113 espécies de Anfíbios, mas o mesmo passa por um acelerado processo de degradação, onde espécies estão sendo extintas antes mesmo de serem conhecidas (OLIVEIRA \& MARQUIS, 2002; NOGUEIRA, et al., 2011).

O estado do Maranhão por sua extensão territorial e posição estratégica de confluência dos domínios fitogeográficos Amazônia, Cerrado e Caatinga, e ainda, por apresentar formações típicas como a Mata de Cocais e Baixada, aparece no cenário nacional como uma das áreas de maior diversidade animal e vegetal (AB'SABER, 1977; MUNIZ, 2006; DIAS, et al., 2009). De modo geral por apresentar um mosaico de biomas e uma riqueza significativa tratando-se de anfíbios, pouco se conhece sobre Herpetofauna, devido ao reduzido número de trabalhos e profissionais da área, no leste maranhense. Dessa forma o presente estudo teve como objetivo conhecer a diversidade de anfíbios (Anuros) presentes na Área de Proteção Ambiental Municipal do Inhamum, um fragmento de cerrado relevante para o estado por ser berço de vários estudos da fauna e flora, com o intuito de servir como acervo bibliográfico e fonte de conhecimento local, onde essas informações possam ser utilizadas para dá continuidade a trabalhos futuros.

\section{MATERIAL E METÓDOS}

A Área de Proteção Ambiental Municipal do Inhamum (APA) é considerada Patrimônio Municipal de Caxias, foi criado pela lei 146/2001 no dia 04 de julho de 2001. Está localizada entre as coordenadas $04^{\circ} 53^{\prime} 30^{\prime \prime}$ de Latitude S e 43⒉'53" de Longitude W, a margem esquerda da BR 316 , com aproximadamente 3500 hectares. Essa região possui uma vegetação de gramíneas em área plana, característico de cerradões, chapadas, cerrado e pequenos pontos de mata fechada que são lugares que proporcionam a sobrevivência da biodiversidade de muitos animais (ALBUQUERQUE, 2012). Além do Cerrado, na área ocorrem fitofisionomia de Floresta Estacional Semidecidual com predominância de babaçuais. Em alguns trechos o babaçu deixa de ocorrer e nesses trechos evidenciam-se manchas de Cerrado e Matas de Galeria (CONCEIÇÃO et al., 2012).

Para amostragem da riqueza de espécies local da área foram realizadas expedições no período de março a julho de 2015 e março a junho de 2016 (Estações chuvosas), utilizando dois métodos de amostragem: armadilhas de interceptação e queda e busca ativa. As armadilhas de interceptação e queda consistem de recipientes enterrados no solo (Pitfalls) e interligados por cercas-guia (Driftlences) (CORN, 1994). As armadilhas instaladas de Interceptação e Queda na área foram compostas de cinco baldes de 60 litros dispostos em forma de "I", sem atrativo, distantes quatro metros entre si, interligados por cerca-guia de 40 centímetros de altura. Foram amostrados quatro pontos, com armadilhas de Interceptação e Queda (AQ), duas na Mata de Galeria e duas no cerrado sujo (Fig.1), onde as mesmas passavam sete dias ativas, sendo vistoriadas diariamente e sete dias desarmadas, seguindo esse ciclo em todo período de amostragem. Foram utilizados 20 baldes divididos igualmente nos dois tipos de áreas (Fig. 2).

Para amostragem dos animais também foi utilizado o método de busca ativa (CRUMP \& SCOTT JR, 1994) durante o período noturno no horário das 18:00 as 23:00h, devido a maior atividade desses organismos durante a noite, sendo estas expedições quinzenais, na Área de Proteção Ambiental Municipal do Inhamum nos dois tipos de área investigados mata de Galeria e cerrado sujo, amostrando vários ambientes presentes em cada área como trilhas, brejos, lagoas, margem de rios e 
riachos. Os anuros foram localizados principalmente por meio de suas vocalizações, método conhecido como busca em sítio reprodutivo (CRUMP \& SCOTT JR. 1994; HEYER et al., 1994; DINIZ, 2015).

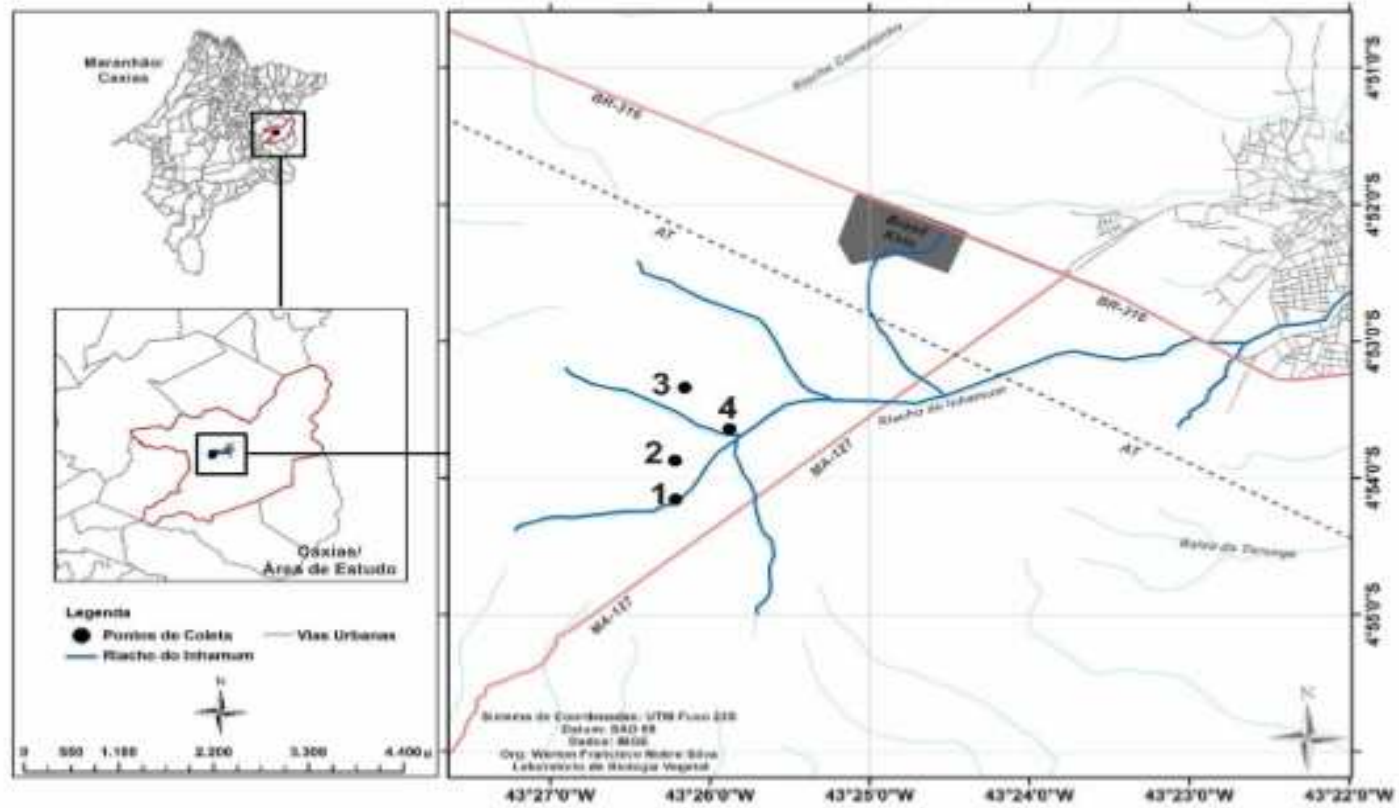

FIGURA 1. Localização dos pontos de coleta com Armadilhas de Interceptação e Queda na APA do Inhamum, com os pontos 1-4 em Mata de Galeria e 2-3 em Cerrado. Fonte: IBGE, 2006 Organização: SILVA ( 2016).

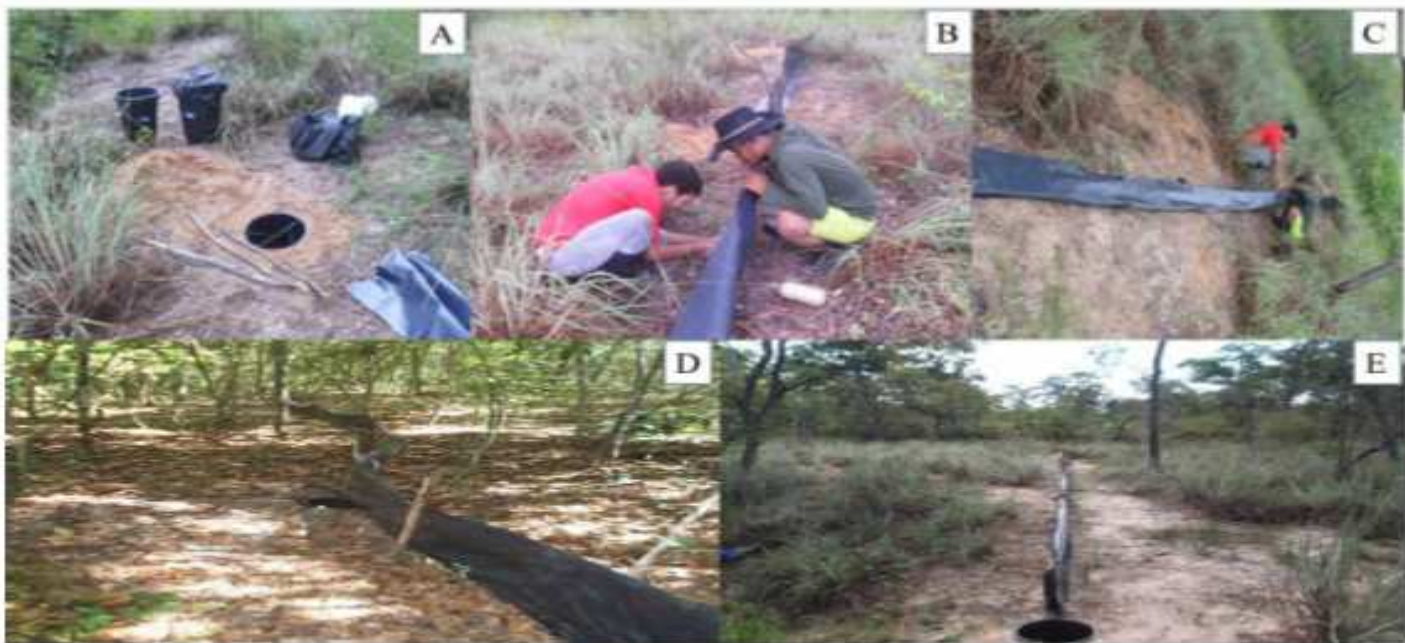

FIGURA 2. Demonstração da construção de Armadilhas de Interceptação e Queda. A) Materiais utilizados para construção das armadilhas; B) Construção das Armadilhas; C) Montagem da Cerca Guia; D) Armadilha em área de Mata Fechada; E) Armadilha em Cerrado pronta. Fonte: CAMPOS et al., (2016).

Os animais capturados durante as buscas ativas e nas armadilhas foram registrados em caderno de campo, anotando-se as principais características de cada indivíduo, como tamanho da espécie, habitat, a hora, data e a atividade de cada animal. Logo após, os anfíbios foram registrados em fotos distintas representando a parte ventral e dorsal para o auxílio da identificação do animal e posteriormente 
devolvidos a seus ambientes, variando o tempo de registro de cada indivíduo de acordo com o número de características registradas, levando em média de 5 à 15 minutos de caracterização. O material biológico que não foi identificado no campo foi coletado e levado para o Laboratório Multiusuário de Ciências Biológicas do CESCUEMA sendo acondicionados em sacos plásticos úmidos com serapilheira em caixas térmicas e identificado em seguida com a ajuda de um especialista na área de herpetologia e com o auxílio de literatura da área como artigos e dissertações, onde os mesmos espécimes foram confirmados a táxon específico, após identificação o material era relocado em seu ambiente coletado, evitando o máximo de stress possível sobre os organismos.

Após a obtenção dos dados, os mesmos foram registrados em Planilhas no Programa Microsoft Office Excel, onde foram submetidos à formação de gráficos e tabelas que caracterizem a diversidade alfa do ambiente como o número de espécies, abundância, local de coleta e armadilha utilizada. Os dados foram discutidos e corroborados com outros autores, buscando perspectivas que expliquem os resultados obtidos.

\section{RESULTADOS E DISCUSSÃO}

Foram amostrados na Área de Preservação Ambiental do Inhamum, 110 espécimes de anfíbios distribuídos em 24 espécies, catalogados em área de Cerrado e Mata de Galeria, sendo registrados tanto em Armadilhas de Interceptação e queda como em Busca ativa diurna e noturna (Quadro 1.). Estudos envolvendo sistemática e taxonomia representam a base do conhecimento sobre biodiversidade, auxiliando na compreensão das espécies existentes, dos padrões de distribuição geográfica e da evolução dos distintos grupos de organismos conhecidos (STURARO, 2009).

QUADRO 1. Lista de táxons de anfíbios amostrados adicionados ao local e método de coleta na APA do Inhamum, Caxias-MA.

\begin{tabular}{c|c|c|c}
\hline Espécie & Nome Vulgar & $\begin{array}{c}\text { Local de } \\
\text { Coleta }\end{array}$ & $\begin{array}{c}\text { Método de } \\
\text { Coleta }\end{array}$ \\
\hline Dendropsophus branneri (Cochran, 1948) & Perereca & M.G & BA \\
\hline Dendropsophus decipiens (Lutz, 1925) & $\begin{array}{c}\text { Perereca de } \\
\text { moldura }\end{array}$ & M.G & BA \\
\hline Dendropsophus leucophyllatus (Beireis, & $\begin{array}{c}\text { Perereca de } \\
\text { moldura }\end{array}$ & M.G & BA \\
\hline Dendropsophus minutus (Peters, 1872) & $\begin{array}{c}\text { Pererequinha- } \\
\text { de-brejo }\end{array}$ & M.G & BA \\
\hline Dendropsophus nanus (Boulenger, 1889) & $\begin{array}{c}\text { Pererequinha- } \\
\text { de-brejo }\end{array}$ & M.G & BA \\
\hline Hypsiboas multifasciatus (Gunther 1859) & $\begin{array}{c}\text { Perereca } \\
\text { cabrinha }\end{array}$ & M.G/C & BA/AQ \\
\hline Hypsiboas punctatus (Schneider, 1799) & $\begin{array}{c}\text { Perereca de } \\
\text { bolinha }\end{array}$ & M.G & BA \\
\hline Hypsiboas raniceps (Cope, 1862) & $\begin{array}{c}\text { Perereca de } \\
\text { Bananeira }\end{array}$ & M.G & BA \\
\hline Leptodactylus andreae (Muller, 1923) & Gia & M.G/C & BA/AQ \\
\hline Leptodactylus hylaedactylus (Cope, 1868) & Sapinho & M.G & BA \\
\hline Leptodactylus macrosternum (Miranda- & Gia Pintada & M.G/C & BA/AQ \\
\hline Ribeiro, 1926) & Gia & M.G & BA/AQ \\
\hline Leptodactylus mystaceus (Spix, 1824) & M.G
\end{tabular}




\begin{tabular}{|c|c|c|c|}
\hline Leptodactylus troglodytes (Lutz, 1926) & Gia & $\mathrm{C}$ & $\mathrm{AQ}$ \\
\hline Leptodactylus vastus (Lutz, 1930) & Gia & M.G/C & $\mathrm{BA} / \mathrm{AQ}$ \\
\hline $\begin{array}{l}\text { Osteocephalus taurinus (Steindachner, } \\
1799)\end{array}$ & Perereca & M.G & BA \\
\hline $\begin{array}{l}\text { Phylomedusa hipochondrialis (Daudin } \\
1800 \text { ) }\end{array}$ & Rã de cera & M.G & BA \\
\hline Physalaemus albifrons (Spix, 1824) & Casote & M.G/C & $\mathrm{BA} / \mathrm{AQ}$ \\
\hline Physalaemus cuvieri (Fitzinger, 1826) & $\begin{array}{l}\text { Casote/rã } \\
\text { cachorro }\end{array}$ & M.G/C & $\mathrm{BA} / \mathrm{AQ}$ \\
\hline Rhinella jimi (Stevaux, 2002) & Sapo-boi & C & BA \\
\hline Rhinella marina (Linnaeus 1758) & Caruru & M.G/C & BA \\
\hline Rhinella mirandaribeiroi (Gallardo, 1965) & $\begin{array}{c}\text { Sapo-boi ou } \\
\text { Cururu }\end{array}$ & C & $\mathrm{AQ}$ \\
\hline Scinax nebulosus (Spix 1824) & $\begin{array}{l}\text { Perereca de } \\
\text { banheiro }\end{array}$ & M.G & BA \\
\hline Scinax ruber (Laurenti, 1768) & $\begin{array}{l}\text { Perereca de } \\
\text { banheiro }\end{array}$ & M.G & $\mathrm{BA} / \mathrm{AQ}$ \\
\hline Scinax $x$-signatus (Spix, 1824) & $\begin{array}{l}\text { Perereca de } \\
\text { banheiro }\end{array}$ & M.G/C & $A Q$ \\
\hline
\end{tabular}

Legenda: C: Cerrado/ M.G: Mata de Galeria/ AQ: Armadilha de Interceptação e Queda / BA: Busca Ativa.

Com o levantamento foram amostradas três famílias: Hylidae, Leptodactylidae e Bufonidae, sendo Hylidae a mais representativa com 13 espécies amostradas (Fig. 3). Os Hilídeos normalmente conhecidos como pererecas, são adaptados para o hábito arborícola, razão pela qual conseguem ocupar com sucesso ambientes de grande heterogeneidade estrutural como as florestas e outros ambientes (SILVANO, 2003).

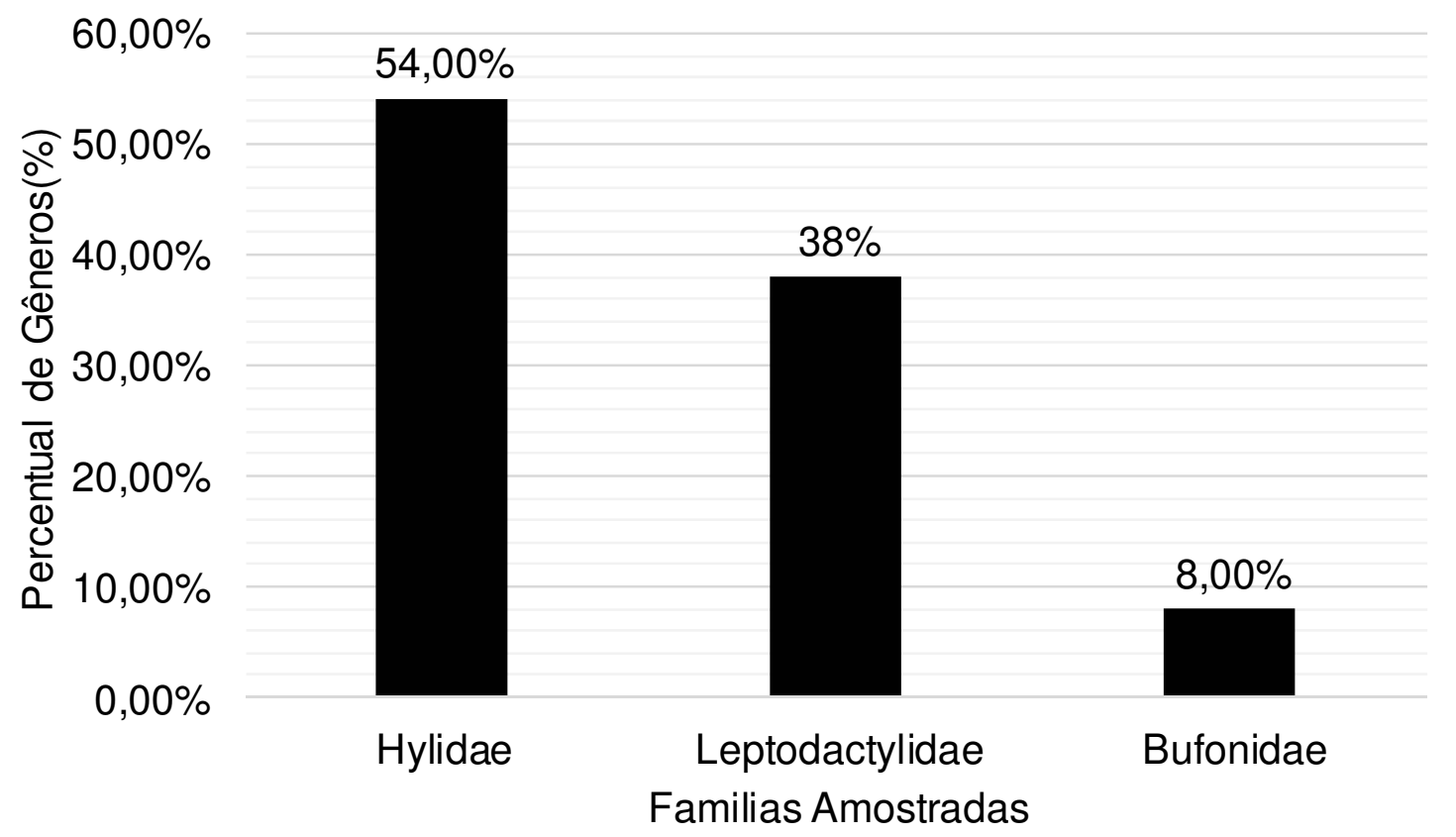

FIGURA 3. Representação gráfica do percentual da diversidade das famílias em nível genérico de anfíbios amostrados na APA do Inhamum, CaxiasMA. 
Ao nível genérico, foram amostrados oito grupos sendo, Leptodactylus o gênero mais representativo com seis espécies, seguido por Dendropsophus com cinco espécies (Fig. 4). O gênero Leptodactylus pertence a anuros terrestres e semiaquáticos que vivem em associação com serapilheiras, sendo geralmente insetívoros, alimento que ocorre com abundância nos ambientes investigados (OLIVEIRA et al., 2012). Dendropsophus é um gênero que está correlacionado com algumas variáveis climáticas como temperatura da água, temperatura do ar, e pluviosidade, apresentando-se de forma significativa com o equilíbrio dessas condições (MASSURA, 2008).

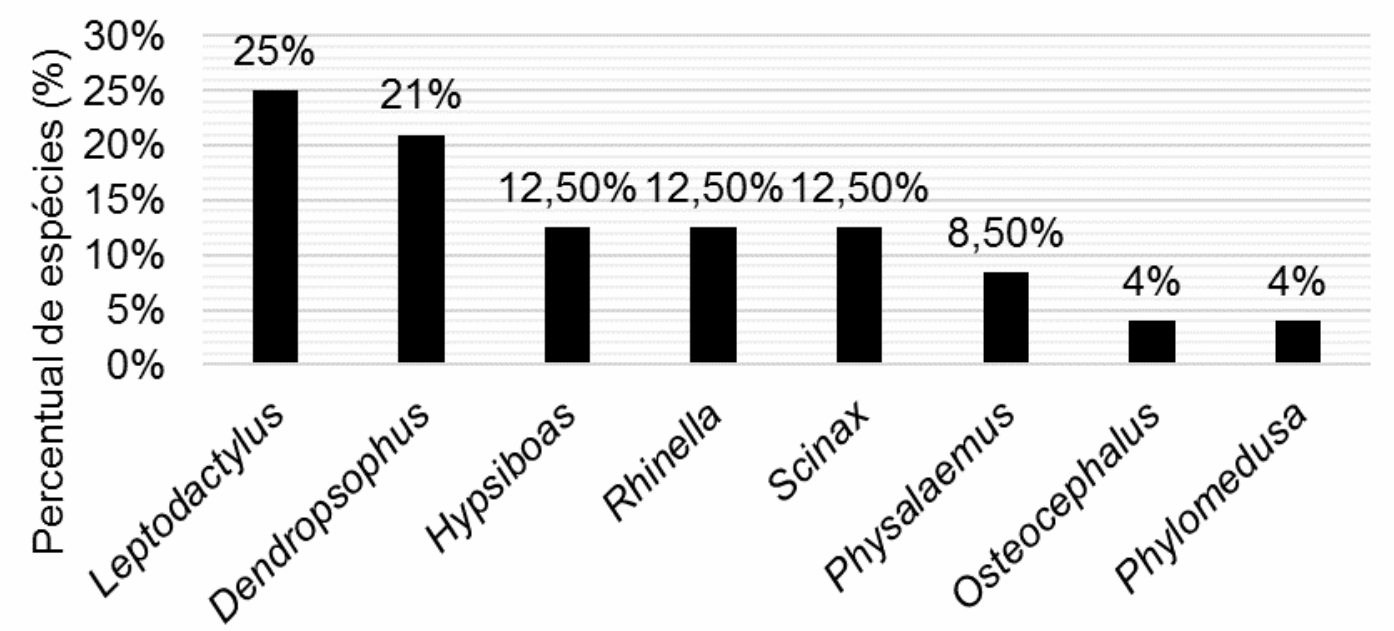

Gêneros amostrados

FIGURA 4. Representação gráfica do percentual da diversidade de gêneros em nível espécies de anfíbios amostrados na APA do Inhamum, Caxias-MA.

A espécie mais representativa dentro da amostragem foi Leptodactylus vastus com 60 indivíduos, cerca de $54,5 \%$ dos indivíduos catalogados. Leptodactylus vastus é um anfíbio adaptado a ambientes antropizados, podendo se fixar em qualquer ambiente, sendo uma espécie fácil de ser observada em esgotos domésticos, possui uma dieta bem diversificada, se alimentando principalmente de insetos o que the propicia um sucesso ecológico (OLIVEIRA et al., 2012).

Quanto ao método de coleta mais eficiente, pode-se observar que a maioria das espécies amostradas foram catalogadas em métodos de busca ativa com 13 espécies, seguido por armadilha de interceptação e queda juntamente com busca ativa com oito espécies encontradas, e apenas três espécies foram amostradas apenas em armadilha de interceptação e queda, vale ressaltar que todos os indivíduos de cada táxon foram coletados em apenas um dos três métodos de coleta desenvolvidos, não havendo sobreposição de animais coletados, os dados são expressos na Fig. 5.

Percebeu-se que as duas metodologias de coleta foram bastantes eficazes juntas para mensurar a Herpetofauna da área e que a busca ativa se torna mais eficaz por explorar maior quantidades de áreas que faz com que a número de espécies encontradas seja maior. Os dados corroboram com o trabalho de MENDES-PINTO \& MIRANDA (2011) que realizaram um levantamento 
Herpetofaunístico de uma área de cerrado em Alto Araguaia, Mato Grosso, Brasil, sendo o método de busca ativa o mais eficaz dentro da amostragem.

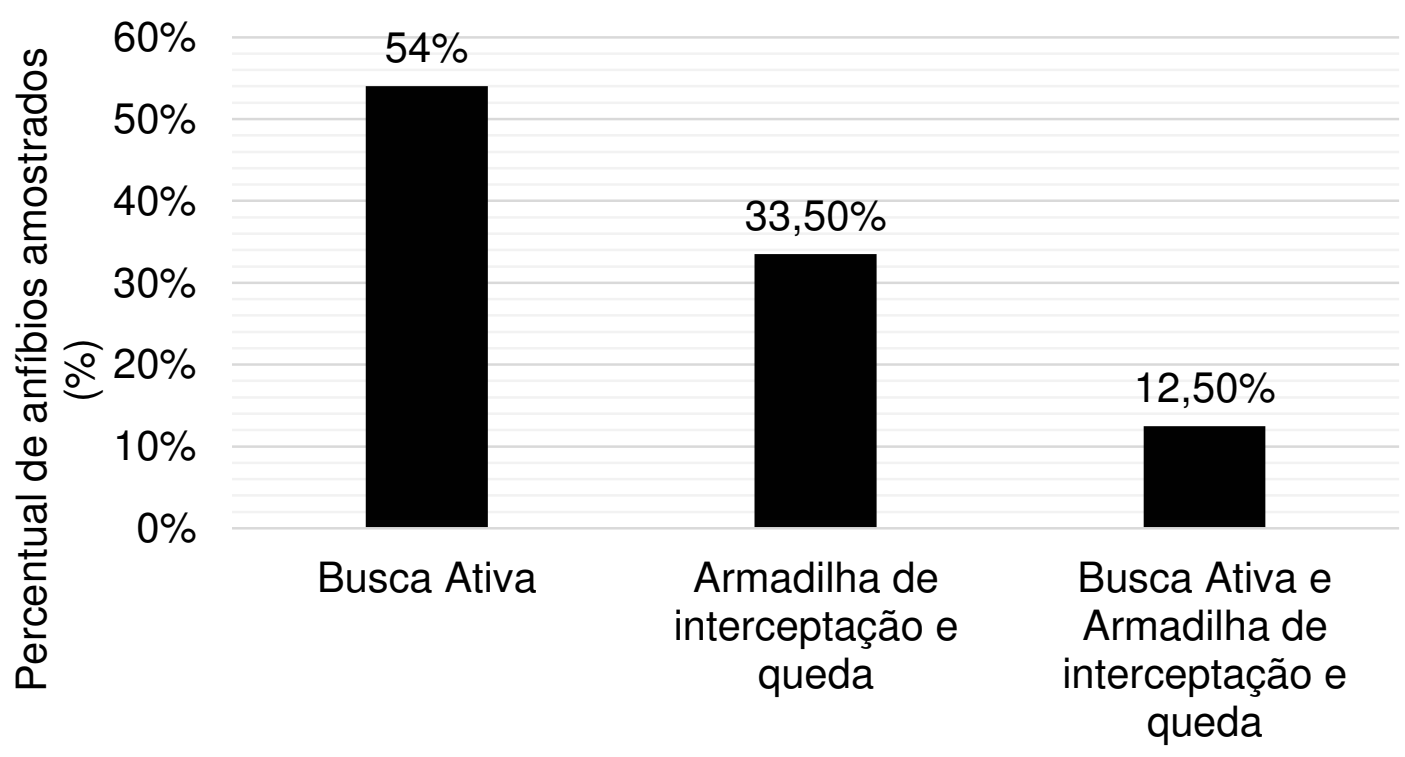

Metódos de coleta

FIGURA 5. Representação gráfica do percentual de anfíbios amostrados por método de coleta na APA do Inhamum, Caxias-MA.

Quanto ao ambiente de coleta pode-se verificar que a área de Mata de Galeria foi a fitofisionomia mais rica em número de espécies catalogados, com 13 espécies amostradas, seguido por oito espécies que foram tanto coletadas em Mata de Galeria como em áreas de Cerrado sujo e por fim três espécies amostradas apenas no Cerrado sujo (Fig. 6). As áreas de Mata de Galeria por possuírem uma maior umidade e também uma maior quantidade de serapilheira propiciam um ambiente bem favorável para a existência dos anuros, criando habitats excelentes para anfíbios se reproduzirem e serpentes desenvolverem o seu nicho. A mata de galeria apresenta fisionomia comumente associada aos solos hidromórficos, com excesso de umidade na maior parte do ano devido ao lençol freático superficial e grande quantidade de material orgânico acumulado (ZARDO, 2010).

O cerrado sujo apresenta cobertura vegetal comparativamente baixa a mata de galeria, mas fornece condições elevadas à iluminação durante o dia que provavelmente permite que os lagartos heliotérmicos e possivelmente anfíbios possam explorar o nicho temporal diurno em sua maior extensão em tais áreas (BERGALLO \& ROCHA, 1993; HATANO et al., 2001). O domínio fitogeográfico apresenta variações fisionômico-florísticas consideráveis, desde formas florestais densas até campos puramente herbáceos, apresentando um teor médio de matéria orgânica e recebendo um incremento anual de resíduos orgânicos provenientes da deposição de folhas durante a estação seca (ZARDO, 2010). 


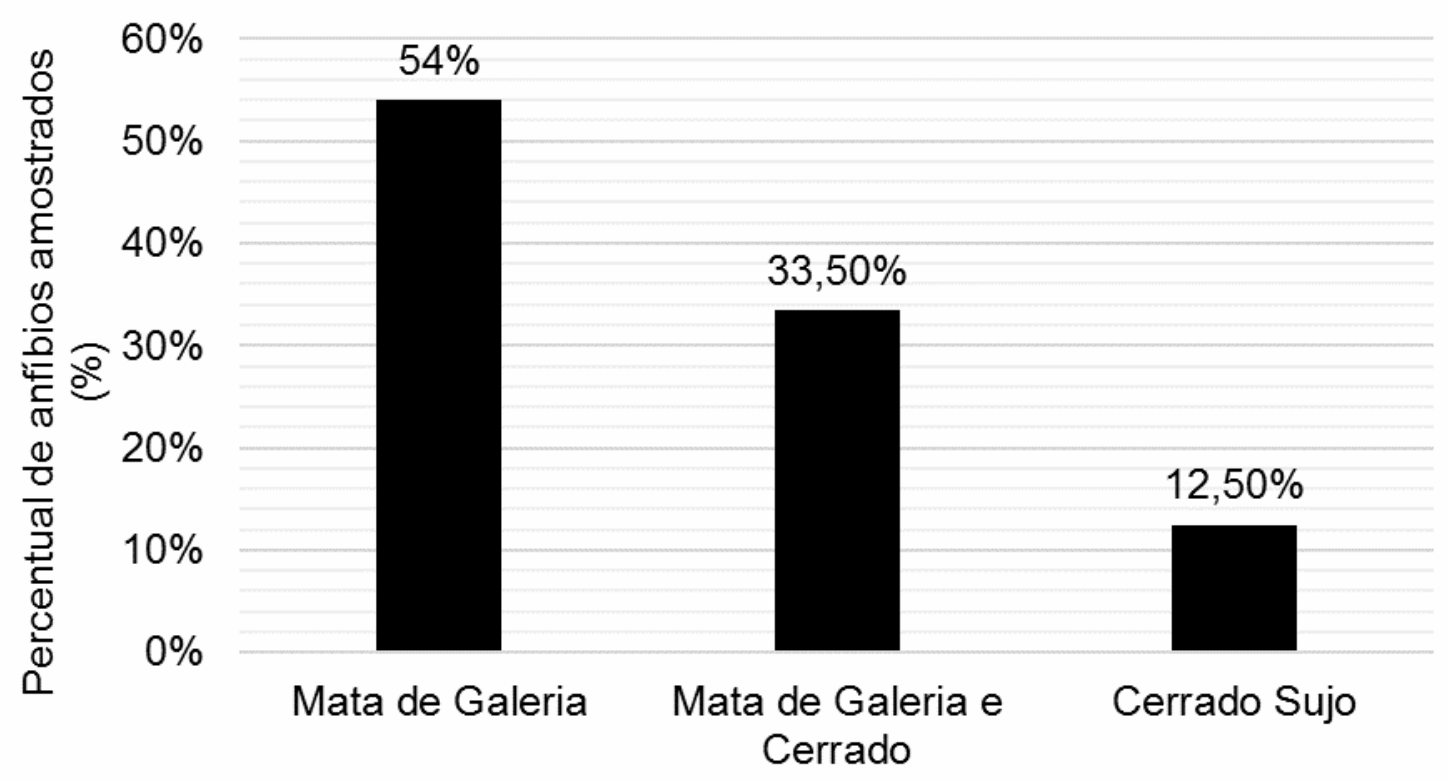

Fitofisionomias de coleta

FIGURA 6. Representação gráfica do percentual de anfíbios amostrados por ambiente de coleta na APA do Inhamum, Caxias-MA.

A riqueza do local, denominada de diversidade alfa amostrada na área de coleta revela o potencial não só da área local, mas do domínio fitogeográfico cerrado, que proporciona condições favoráveis para o desenvolvimento desses organismos e principalmente para os meios reprodutivos. Os anfíbios, especialmente os anuros, são considerados o grupo de tetrápodes com a maior diversidade de modos reprodutivos, os quais apresentam como definição a combinação de fatores relacionados à ovoposição e desenvolvimento, incluindo sítio de reprodução, relacionando a várias características do ovo e da desova, à taxa e duração do desenvolvimento, ao estágio e tamanho dos eclodentes e ao tipo de cuidado parental (DUELLMAN, 1985).

\section{CONCLUSÃO}

A APA apresenta uma diversidade significativa de anfíbios sendo amostrados 24 espécies. A família, gênero e espécie mais representativo foram respectivamente: Hylidae, Leptodactylus e Leptodactylus vastus, grupos biológicos com ampla distribuição geográfica e diversidade alta, tratando do número de espécies.

Observou-se que as espécies principalmente de anuros apresentam-se em maior quantidade na Mata de Galeria devido suas características abióticas, no entanto o Cerrado sujo detém uma quantidade de espécimes significativas e que também se demonstram relevantes. O método de Busca Ativa mostrou-se o mais eficaz, com um maior número de espécimes amostradas, mas ressalta-se que o método de armadilhas de interceptação e queda, contribuiu significativamente para uma maior amostragem.

O presente estudo verificou que a diversidade de anfíbios além de ser rica em número de espécie deve ser preservada, pois a APA sofre constantes queimadas em determinados períodos do ano, o conhecimento dessa composição faunística é o primeiro passo para uma possível conservação dessa diversidade biológica, por isso faz-se relevante e necessário o presente estudo. As informações 
sobre os espécimes, principalmente a ocorrência em determinados ambientes servem de base para novos trabalhos sobre a Herpetofauna não só na área de estudo, mas no Cerrado, contribuindo com a taxonomia e Ecologia de vários grupos.

\section{REFERÊNCIAS}

AB'SABER, A. N. Os domínios morfoclimáticos na América do Sul. Geomorfologia, v. 52, p. 1-21, 1977. Disponível em: https://pt.scribd.com/doc/54399216/ Acesso em: 24/03/2017.

ALBUQUERQUE, A. Riacho ponte e a Área de Proteção Ambiental Municipal do Inhamum, Caxias/MA. In: BARROS, M. C.; et al. Biodiversidade na Área de Proteção Ambiental Municipal do Inhamum. São Luís: UEMA p.13-20, 2012.

ÁLVARES, G. F. R. Taxonomia, distribuição geográfica potencial e conservação das espécies de Phyllomedusa do grupo hypocondrialis. Dissertação (Mestrado) Brasília. $\quad$ p. $109,2009 . \quad$ Disponível em: http://repositorio.unb.br/bitstream/10482/4494/1/2009_GuilhermeFajardoRoldaoAlvar es.pdf Acesso em: 24/03/2017.

BERGALLO, H. G.; ROCHA, C. F. D. Activity pattern and body temperature of two sympatric lizards with different foraging tactics in southeastern Brazil. AmphibiaReptilia. v. 4, p. 312-315, 1993. Disponível em: http://booksandjournals.brillonline.com Acesso em: 25/03/2017.

BURKETT, D. W.; THOMPSON, B. C. Wildlife association with human-altered water sources in semiarid vegetation communities. Conservation Biology. v. 8, p. 682690, $1994 . \quad$ Disponível em: https://www.jstor.org/stable/2386510?seq=1\#page_scan_tab_contents Acesso em:24/03/2017.

CONCEIÇÃO, G. M.; RUGGIERI, A. C.; GUIMARÃES, E. R. Melastomataceae da Área de Proteção Ambiental Municipal do Inhamum, Caxias, Maranhão. Revista de Biologia e Farmácia. v. 4, n. 2, p. 83-88, 2012. Disponível em: http://sites.uepb.edu.br/biofar/download/v4n2-2010 Acesso em: 24/03/2017.

CORN, P. S. Straight-line dritl fences and pitfall traps. In: HEYER, W. R.; DONNELY, M. A.: McDIARMID, R. W.; HAYEK, L. A.; FOSTER, M. Measuring and monitoring biological diversity: standard mcthods for amphibians. Washington, D.C., Smithsonian Institution Press, p. 109-117, 1994. Disponível em: www.fort.usgs.gov/publication/2611 Acesso em: 25/03/2017.

CORRÊA, L. L. C. Levantamento preliminar faunístico no parque ambiental Galeno Santos Mota, Rio Grande do Sul. Revista Eletrônica em Gestão, Educação e Tecnologia Ambiental - UFSM. v. 18, n. 1, p. 97, 2013. Disponível em: http://dx.doi.org/10.5902/2236117010767

CRUMP, M. L.; SCOTT JR, N. J. Visual encounter surveys. In: HEYER, W. R.; DONNELY, M. A.: McDIARMID, R. W.; HAYEK, L. A.; FOSTER, M. Standard methods for amphibians. Smithsonian Institution Press. p. 84-92. 1994. Disponível 
em: http://www.nri.org/projects/publications/ecological_methods/m_chapter11_en.pdf Acesso em: 24/03/2017.

DIAS, P. A.; SANTOS, C. L. C.; RODRIGUES, F. S.; ROSA, L. C.; LOBATO, K. S.; REBÊLO, J. M. M. Espécies de moscas ectoparasitas (Diptera, Hippoboscoidea) de morcegos (Mammalia, Chiroptera) no estado do Maranhão. Revista Brasileira de Entomologia. v. 53, p. 128-133, 2009. Disponivel em: http://dx.doi.org/10.1590/S0085-56262009000100027

DINIZ, P. C. Métodos de Amostragem da Herpetofauna, algumas dicas e orientações para estudantes e profissionais com pouca ou nenhuma experiência de campo. (Monografia) p. 24, 2015. Disponível em: http://www3.izabelahendrix.edu.br/ojs/index.php/aic/article/view/813 Acesso em: 24/03/2017.

DRUMMOND, G. M. Diversidade Biológica - Minas Gerais - Atlas. $2^{\circ} \mathrm{ed}$. Fundação Biodiversitas. Belo Horizonte, v. 502, p. 222, 2005.

DUELLMAN, W. E. Reproductive modes in anuran amphibians: phylogenetic significance of adaptive strategies. South African Journal of Science. v. 81, p. 174178, 1985. Disponível em: www.researchgate.net/publication/291778785 Acesso em: 24/03/2017.

HATANO, F. H.; VIRCIBRADIC, D.; GALDINO, C. A. B.; CUNHA-BARROS, M.; ROCHA, C. F. D.; VAN-SLUYS, M. Thermal ecology and activity patterns of the lizard community of the Restinga of Jurubatiba, Macaé, RJ. Revista Brasileira de Biologia. v. 61, n. 2, p.287-294, 2001. Disponível em: http://dx.doi.org/10.1590/S0034-71082001000200011

HEYER, W. R.; DONELLY, M. A; MCDIARMID, R. W; HAYEK, L. A. C.; FOSTER, M. $S$. Measuring and monitoring biological diversity: standart methods for Amphibians. Smithsonian Institution Press, p.118-125,1994.

JIM, J. Aspectos ecológicos dos anfíbios registrados na região de Botucatu, São Paulo (Amphibia, Anura). (Tese de Doutorado). Universidade de São Paulo, São Paulo, p. 332, 1980. Disponível em: http://bdpi.usp.br/single.php?_id=000710244 Acesso em: 24/03/2017.

LIDDLE, M. J.; SCORGIE, R. A. The effects of recreation on freshwater plants and animals: A review. Biological Conservation. v. 17, p. 183-206, 1980. Disponível em: http://www.sciencedirect.com/science/article/pii/0006320780900555 Acesso em: 24/03/2017.

MASSURA, T. Y. M. Anatomia do Aparelho Reprodutor Masculino de Dendropsophus nanus e Dendropsophus minutus (Anura; Hylidae) durante o ciclo reprodutivo. Dissertação (Mestrado) Instituto de Biociência, Letras e Exatas da Universidade Estadual paulista. São Paulo, p. 75, 2008. Disponível em: https://repositorio.unesp.br/handle/11449/87573 Acesso em: 26/03/2017. 
MENDES-PINTO, T. J.; MIRANDA, I. M. Levantamento Herpetofaunístico de uma Área de Cerrado em Alto Araguaia, Mato Grosso, Brasil. Revista de Biologia e Farmácia. v. 6, n. 2, p. 129-137, 2011. Disponível em: http://sites.uepb.edu.br Acesso em: 28/04/2017.

MUNIZ, F. H. A vegetação da região de transição entre a Amazônia e o Nordeste: diversidade e estrutura. In: MOURA, E. G. Agroambientes de transição entre o Trópico Úmido e o Semi-árido do Brasil: atributos, alterações e uso na produção familiar. 2 ed. São Luís: Programa de Pós-graduação em Agroecologia/UEMA, v. 1, p. 53-69, 2006. Disponível em: http://www.iica.org.br/docs/publicacoes/publicacoesiica/agroabientestransicao.pdf Acesso em: 27/03/2017.

NEVES, M. O. Anfíbios da Serra Negra, Zona da Mata de Minas Gerais e padrões de Distribuição dos Anuros, da Serra da Mantiqueira e Sul do Espinhaço. Dissertação (mestrado). Viçosa MG, p. 76, 2015. Disponível em: http://www.locus.ufv.br/bitstream/handle/123456789/7244/texto\%20completo.pdf?se quence=1 Acesso em: 24/03/2017.

NOGUEIRA, C.; RIBEIRO, S. R.; COLLI, G. R. Répteis do Cerrado Squamate: Revisão de dados de distribuição e novas insights sobre biogeografia, endemismo e conservação em savana. Neotropical hotspot. v. 38, p. 1907-1922, 2011.

OLIVEIRA, H, H, P.; SOUZA, C, C, N.; BASTOS, R, P. Citogenética Comparativa das Famílias Leptodactylidae e Hylidae do Cerrado Goiano. Goiania Estudos. v. 339, n. $2, \quad$ p. $\quad 9,2012 . \quad$ Disponível em: seer.ucg.br/index.php/estudos/article/download/2593/1593 Acesso em: 26/03/2017.

OLIVEIRA, P. S.; MARQUIS, R. J. Cerrado Herpetofauna. In: The Cerrados of Brazil: Ecology and Natural History of a Neotropical Savanna. Columbia University Press. p. 223-241, 2002. Disponível em: https://books.google.com.br/books/about/The_Cerrados_of_Brazil.html?id=gp2eBdN OtSOC\&redir_esc=y Acesso em: 24/03/2017.

SBH. Lista de espécies de anfíbios do Brasil. Sociedade Brasileira de Herpetologia (SBH). 2014. Disponível em: www.sbherpetologia.org.br. Acesso em: 10/02/2017.

SILVANO, D, L.; BRUNO, V, S. Diversidade e distribuição de Anfíbios na Mata Atlântica do Sul da Bahia. Biomonitoramento. p. 22, 2003. Disponível em: http://www.rbma.org.br/anuario/pdf/mata_09_anfibios.pdf Acesso em: 20/03/2017.

STURARO, M. J. Revisão taxonômica do complexo Gonatodes concinnatus (Reptilia: Sphaerodactylidae). Dissertação (Mestrado em Zoologia) - Universidade Federal do Pará, p. 104, 2009. Disponível em: http://repositorio.ufpa.br/jspui/handle/2011/3532 Acesso em: 25/03/2017.

SUGAI, J. M. M. Comunidade de anuros e influência da estrutura ambiental de veredas na composição de espécies em parte da bacia do Alto Taquari, Norte 
do mato grosso do sul. p. 77, 2010. Dissertação (pós-graduação em Ecologia e Conservação) - Universidade Federal de Mato Grosso do Sul. p. 2010. Disponível em: https://sistemas.ufms.br/sigpos/portal/trabalhos/download/4/cursold:11 Acesso em: 28/03/2017.

VAN DAN, H; BUSKENS, R. F. M. Ecology and management, of moorland pools: balancing acidification and eutrofication. Hydrobiologia. v. 265, p. 225-263, 1993. Disponível em: https://link.springer.com/chapter/10.1007\%2F978-94-011-2042-5_12 Acesso em: 26/03/2017.

VAN ROOY, P. T. J. C.; STUMPEL, A. H. P. Ecological impact of economic development on sardinian herpetofauna. Conservation Biology. v. 9, p. 263-269, 1995. Disponível em: http://onlinelibrary.wiley.com/doi/10.1046/j.15231739.1995.9020263.x/abstract Acesso em: 26/03/2017.

WATSON, G. F; DAIES, M; TYLER, M. J. Observations on temporary Waters in northwestern Australia. Hydrobiologia, v. 299, p. 53-73, 1995. Disponível em: https://link.springer.com/article/10.1007/BF00016886 Acesso em: 28/03/2017.

ZARDO, D. C. Comunidade de artrópodes associado a serapilheira e mata de galeria, na estação ecológica serra das Araras Mato Grosso Brasil. Revista Uniara. v. 13, n. 2, p. 9, 2010. Disponível em: http://www.revistarebram.com/index.php/revistauniara/article/view/143 Acesso em: 24/03/2017. 